\title{
Comparative analysis of soil-sampling methods used in precision agriculture
}

\author{
José Roberto Moreira Ribeiro Gonçalves, ${ }^{1}$ Gabriel Araújo e Silva Ferraz, ${ }^{2}$ Étore Francisco Reynaldo, ${ }^{3}$ \\ Diego Bedin Marin, ${ }^{2}$ Patrícia Ferreira Ponciano Ferraz, ${ }^{2}$ Manuel Pérez-Ruiz, ${ }^{4}$ Giuseppe Rossi, ${ }^{5}$ \\ Marco Vieri, ${ }^{6}$ Daniele Sarri ${ }^{6}$
}

\author{
${ }^{1}$ Department of Architecture and Engineering, Laureate International - IBMR, Barra da Tijuca, RJ, Brazil; \\ ${ }^{2}$ Department of Agricultural Engineering, Federal University of Lavras, University Campus, Lavras, MG, Brazil; \\ ${ }^{3}$ Field Equipment Manager - Syngenta, Uberlândia-MG, Brazil; ${ }^{4}$ Area of Agroforestry Engineering, Technical School \\ of Agricultural Engineering (ETSIA), Universidad de Sevilla, Sevilla, Spain; ${ }^{5}$ Department of Agriculture, Food, \\ Environment and Forestry, University of Florence, Florence, Italy; ${ }^{6}$ Department of Agricultural, Food, Environment \\ and Forestry (DAGRI), Biosystem Engineering Division, University of Florence, Florence, Italy
}

\begin{abstract}
The aim of this study was to compare three different soil-sampling methods used in Precision Agriculture and their environmental impact on agricultural production. The sampling methods used were: zone management by elevation, grid sampling (GS) and sampling oriented by apparent soil electrical conductivity (OS). Three different fields were tested. When the recommendations were compared, a significant difference among the suggested doses was observed. This indicated the need to improve the soilsampling techniques, since there were doubts about input deficits or overdoses, regardless of the technology studied. The GS method was the most environmentally viable alternative for phosphorus $(\mathrm{P})$ compared to other methods and the OS presented as the better option for potassium $(\mathrm{K})$ and nitrogen $(\mathrm{N})$. However, the use of soil sensors appeared to be a viable technology that needs further improvement in order to improve productivity and, hence, economic and environmental benefits.
\end{abstract}

Correspondence: Daniele Sarri, Department of Agricultural, Food, Environment and Forestry (DAGRI), Biosystem Engineering Division, University of Florence, Piazzale delle Cascine 15, 50144 Florence, Italy.

Tel.: +39.0552 .755882$

E-mail: daniele.sarri@unifi.it

Key words: Management zones; grid sampling; environmental impact; electrical conductivity; soil proximity sensor.

Acknowledgements: the authors thank the Agricultural Foundation for Agricultural Research (FAPA), the Federal University of Lavras (UFLA), the Rural Federal University of Rio de Janeiro, the University of Sevilla and University of Firenze (UniFI).

Received for publication: 21 September 2020.

Accepted for publication: 15 January 2021.

(C) Copyright: the Author(s), 2021

Licensee PAGEPress, Italy

Journal of Agricultural Engineering 2021; LII:1117

doi:10.4081/jae.2021.1117

This article is distributed under the terms of the Creative Commons Attribution Noncommercial License (by-nc 4.0) which permits any noncommercial use, distribution, and reproduction in any medium, provided the original author(s) and source are credited.

\section{Introduction}

Although the modest technological availability, precision agriculture (PA) is a modern concept of agricultural management (Pierpaoli et al., 2013). It is considered one of the ten greatest revolutions in agriculture (Crookston, 2006), as it provides for more reliable decision-making (Pierce and Nowak, 1999), affords more accurate fertiliser application, and, therefore, production cost savings (Catania et al., 2020). Also, it creates opportunities for intensive data collection, provides accurate tracking and production adjustments, and allows management zones to be defined for customized input administration (Mulla, 2013).

According to Gomes and Barizon (2014) both people and the environment can be damaged severely by the misuse of compounds, such as $(\mathrm{N}),(\mathrm{P}),(\mathrm{K})$; these fertilizers usually reach the water bodies due to soil accumulation and end up in streams and rivers (Simplício, 2015). As described by Artuzo (2015), only $17.28 \%$ of farmers understand the need for environmental improvement by reducing the use of fertilizers, which is becoming a relevant issue.

Therefore, agricultural production and the risk of environmental contamination can be optimized by implementing PA (Ragagnin et al., 2010; Sanchez et al., 2012), thus avoiding the use of excessive doses of nutrients, which would leach or end in water bodies (Klein and Agne, 2012; Vargas, 2012; Biesdorf et al., 2016). Silva (2009) found that the rational use of fertilizers in PA makes it possible to reduce pollution by up to $73 \%$ and costs by up to $71 \%$.

An integrated management of nutrients promotes sustainable production and, consequently, the protection of the environment (Zhang et al., 2010). Celinski (2008) evaluated the need to search for new technologies aimed at reducing production costs and negative environmental impacts. In this context, PA shows a direct relationship between economic gain and environmental benefit with the efficient use of agricultural inputs (Costa and Guilhoto, 2013).

However, few studies evaluated the positive impacts of PA on the environment. This situation can be considered alarming, since Brazil is the largest fertilizer consumer worldwide (Beras, 2014), and the overuse of fertilizers is directly related to the environmental impacts of agriculture (Mulla, 2013; Artuzo, 2015).

In order to refine management practices and evaluate agricultural effects, it is crucial to understand the spatial variability of soil properties, which is a relevant factor in a production system aimed at sustainability through site-specific management (Ferraz et al., 2019). Moreover, spatial characteristics allow us to quantify several natural phenomena (Wang et al., 2018). Studies conducted 
by Sanchez et al. (2012) showed that map generation for variable rate application of inputs proves to be more economically and environmentally efficient compared to average-based applications.

According to Keskin and Sekerli (2016), soil sampling methods are an essential part of PA, but are sometimes poorly understood and incorrectly used. Therefore, it is interesting to carry out studies to understand soil sampling methods better. Grid sampling (GS) and management zone sampling are the most commonly used soil sampling methods to identify soil properties in PA (Ragagnin et al., 2012).

The GS is widely used as a sampling method for PA proposes. According to Zinkevičius (2018), this method consists of dividing an area into various square or rectangular sections, where farmers can sample each section. Walton et al. (2010) found that agribusiness firms, which wish to continue using the grid soil sampling technology, could benefit from promoting complementary technologies and practices based on site-specific information obtained from this kind of sampling.

In management zone sampling, an area is divided into subareas or homogeneous areas to apply uniform input doses (Prado et al., 2010). Therefore, these areas present similar potential responses, and have the same limitation and agricultural risks (Miqueloni et al., 2015). These management zones can be obtained in different ways, such as based on altitude, crop yield, and soil attribute maps (Cherubin et al., 2015). Zhang et al. (2010) stated that the knowledge of spatial distribution associated with the definition of management zones through regionalized maps could result in a more efficient application of agricultural fertilizers, a reduction of input costs, an optimized use of fertilizers as well as economic and environmental gains. Management zones could also be defined by soil electrical conductivity sensors (Mallarino and Wittry, 2004), which are already available to farmers (Ferraz et al., 2019). According to Mulla (2013), the use of high technology, such as soil sensors to optimize the use of fertilizer, appears a viable alternative to promote the mitigation of increasing environmental pollution .

According to Mallarino and Wittry (2004), researchers, farmers and technicians recognize that spatial variability in soil properties leads to differences in soil-test levels, fertilizer requirements, and crop yield within a field. Therefore, the use of different sampling methods could also affect the observation of fertilizer requirements and the fertilizer application rates.

Consequently, it will lead to different environmental impacts. Therefore, it would be interesting to compare the PA sampling methods commonly used, such as grid-sampling, altitude management zone, and soil electrical conductivity management zones. The sampling method conventionally used in Brazil (zigzag) does not provide certainty in the application of correctives and fertilizers. It could recommend a lower or higher quantity of products compared to the actual nutritional need of the crops. In this case, the yield can decrease with low doses and/or the environmental impact can increase due to excessive doses of nutrients. The methods presented in this paper are similar from the technical point of view, because they use information obtained through technological tools, such as altitude maps, georeferenced sampling, and electrical conductivity. As a result, they are superior to the conventional method, because they represent an improvement in soil sampling methods, and can lead to better in terms of the environment impact. Therefore, this study aimed to compare three different soil-sampling methods used in PA and their environmental impact on agricultural production in three different areas.

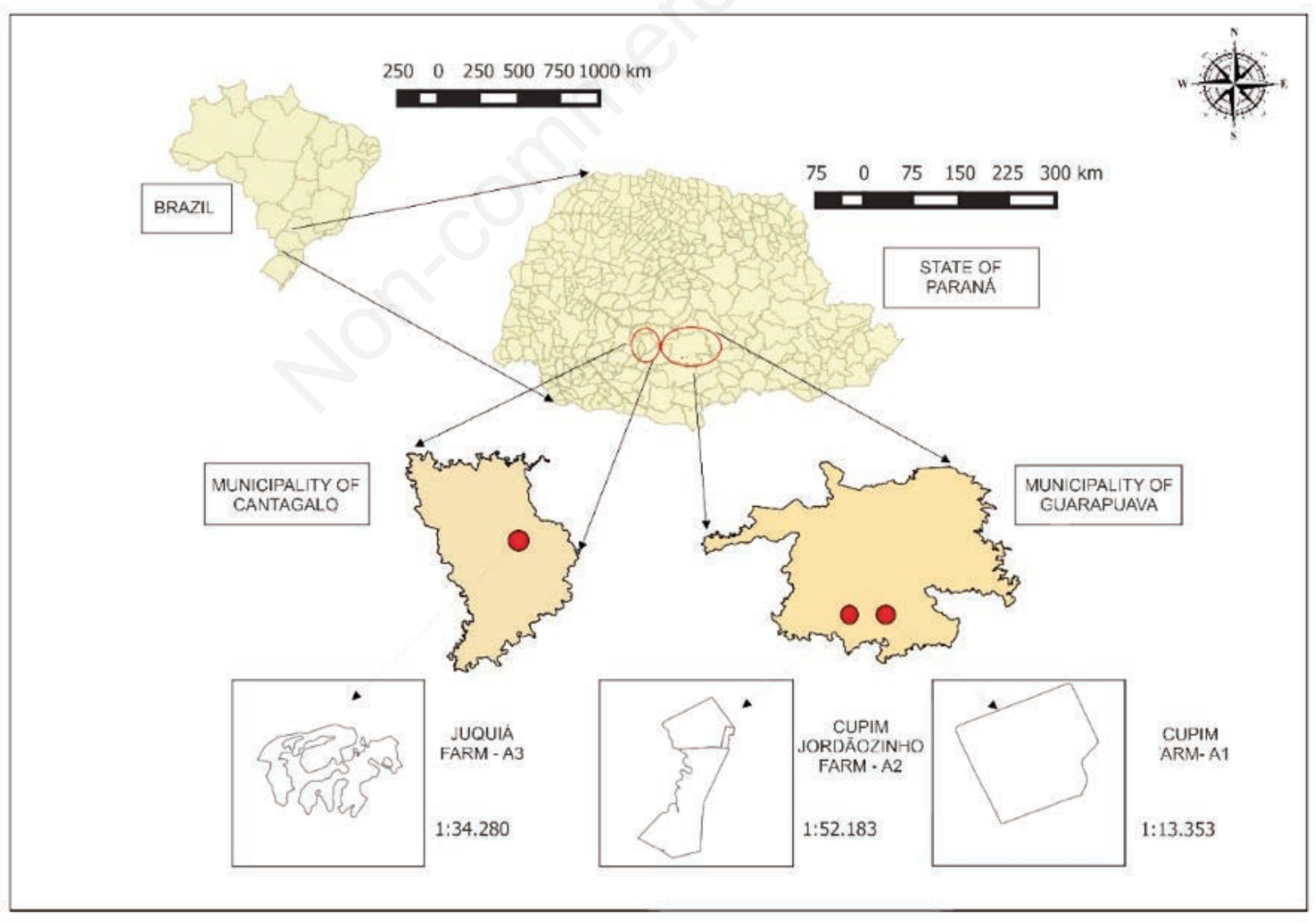

Figure 1. Geographical location of the study areas. 


\section{Materials and methods}

This study was performed in two farms (Cupim and Juquiá) in the municipalities of Guarapuava and Cantagalo, both in the Paraná state, in Brazil. According to the Köppen classification (Cfa), this region is characterized by a humid subtropical climate. The annual average temperature is $18^{\circ} \mathrm{C}$, with a maximum of $36^{\circ} \mathrm{C}$ and a minimum of $6.8^{\circ} \mathrm{C}$ and annual average precipitation of 1600 $\mathrm{mm}$. The elevation of the region is between 800 and $1200 \mathrm{~m}$. The soil of both areas is characterized as Haplustox, with a prominent 'A' horizon, smooth undulating relief and basalt substrate, with a textural class varying from clayey to very clayey (Fontoura et al., 2015). The experiments were performed in three different areas in the two farms (Figure 1), on November 10, 2015. In order to best understand, compare and analyze the results, the areas were named A1 (Cupim Farm, with 154.82 ha, geographic coordinates $25^{\circ} 32^{\prime}$ 66" S and 51 34' 65" W, 1054.65 m altitude), A2 (Cupim Farm, Jordãozinho plot, with an area of 18.64 ha, geographic coordinates $25^{\circ} 31^{\prime} 74$ " $\mathrm{S}$ and $51^{\circ} 30^{\prime} 49^{\prime}$ ' W, $1100.83 \mathrm{~m}$ altitude), and A3 (Juquiá Farm, with 62.63 ha, $25^{\circ} 16^{\prime} 45$ 40" S and 52 6' $01^{\prime \prime}$ W, $798.85 \mathrm{~m}$ altitude). Crop rotation had been ongoing for at least 16 years in these areas and was based on the alternation of rotating crops, such as soybean, oat, maize, wheat, and barley. Sowing was performed twice a year in the months from June to August and from October to December, while harvests were in November, February, and March, according to the crop rotations.

In the study areas, three sample methods were applied for comparative purposes, namely altitude management zones (MZA), GS, and oriented sampling (OS). The number of samples for each sampling method are reported in Table 1.

Since harvest maps can provide altimetry data, in order to collect the soil samples for the MZA method, the zones were firstly defined based on elevation data obtained through these maps. Then, the area was divided into three zones: high, medium and low altitude (Figure 2). The criteria used for the altitude classification was related to the levels that represents the altitude variability in the field that was possible to study. The soil samples were collected through a zigzag pattern in each zone by taking from 11 to 15 subsamples and composite samples representative of each zone after homogenization. As to the GS method, sample grids of $100 \times 100 \mathrm{~m}$ were primarily defined with one collection point per hectare and generated by the grid-sampling tool of SMS Advanced software version 15.1 (Ag Leader Technology, Curitiba, Brazil) (Figure 3). Subsequently, 158 georeferenced sample points were obtained for area A1, 23 for area A2, and 65 for area A3. At each georeferenced point, from 11 to 15 subsamples were collected, which were properly homogenized and formed a composite sample representative of the sampled point. Samples and subsamples were withdrawn at depths from 0 to $0.20 \mathrm{~m}$ using a soil auger and containers for homogenization.

For the OS method, the management zones were defined after sampling electrical conductivity data for the area. This sampling was made with the soil electrical conductivity sensor VERIS 3100 (Veris Technologies, Salina, USA). The VERIS 3100 equipment consisted of six rotating discs, arranged side by side along one axis that works at $7 \mathrm{~cm}$ depth. This equipment was calibrated according to the manufacturer's instructions and worked by emitting an electrical current from the two intermediate disks. Two internal disks and another two external disks detected the potential difference, which occurred in the electromagnetic field, which was generated in the soil due to the applied electrical current. The pair of internal discs integrated the resistance between depths of 0 and $0.3 \mathrm{~m}(\mathrm{ECa}$ 30), while the pair of external discs integrated the resistance between 0 and $0.9 \mathrm{~m}$ (ECa 90). The sensor used was coupled and pulled by an agricultural tractor. This equipment also had an integrated GNSS system, model Trimble R6 with horizontal precision of $3 \mathrm{~mm}$ and vertical precision of $3.5 \mathrm{~mm}$, which allowed the ECa to be georeferenced and correlated with the sampling points, through the information concerning latitude, longitude and altitude

Table 1. Number of samples for each method for each area.

\begin{tabular}{lccc} 
Area & $\begin{array}{c}\text { Altitude } \\
\text { management } \\
\text { Zones }\end{array}$ & $\begin{array}{c}\text { Sampling methods } \\
\text { Grid } \\
\text { sampling }\end{array}$ & $\begin{array}{c}\text { Oriented } \\
\text { sampling }\end{array}$ \\
A1 & 3 & 158 & 5 \\
A2 & 3 & 23 & 5 \\
\hline A3 & 3 & 65 & 5 \\
\hline
\end{tabular}

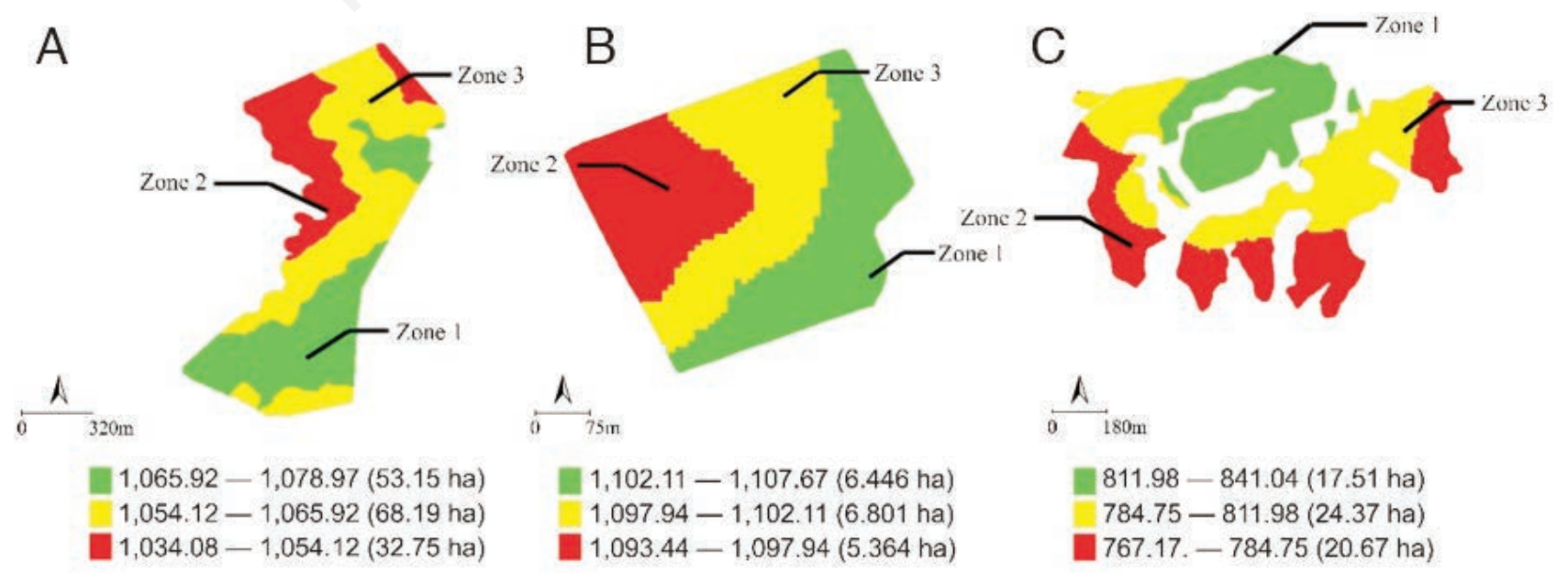

Figure 2. Representation of the altitude-based management zones of areas A1 (A), A2 (B), and A3 (C). 
(Machado et al., 2006). This equipment was used in parallel lines spaced 30 meters from each other at a speed of $9 \mathrm{~km} / \mathrm{h}$. Consequently, the sample density of ECa was 320 points per hectare (Figure 4). After reading ECa, the data were interpolated by the punctual Kriging method (CELINSK, 2008) by the software Vesper 1.6. Then, the experimental semivariograms were developed for each interpolated point followed by the spatial variability maps of the ECa that were used to orient the collection of soil samples (Figure 5).

The chemical elements required for soil fertility corrections for all the methods were determined based on the recommendations suggested by the (Empresa Brasileira de Pesquisa Agropecuária, 1997). The soil fertility corrections of $\mathrm{P}, \mathrm{K}$ and $\mathrm{N}$ were carried out aiming at the high-performance zone that is where needs of the soil
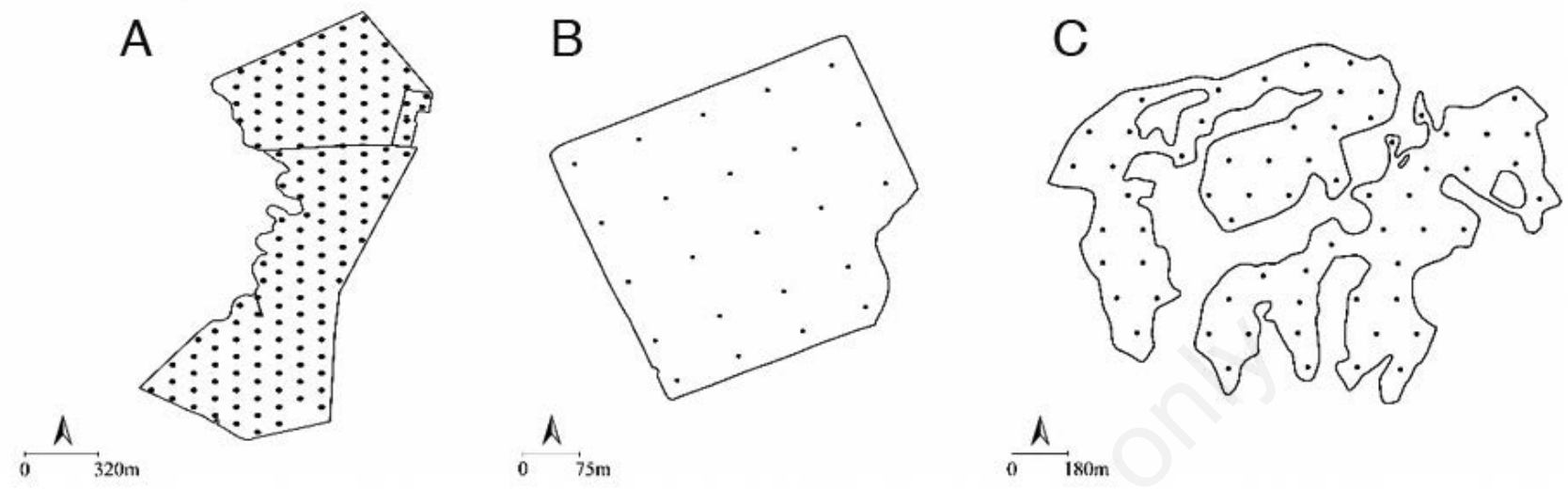

Figure 3. Representation of areas A1 (A), A2 (B), and A3 (C) sampling grids.
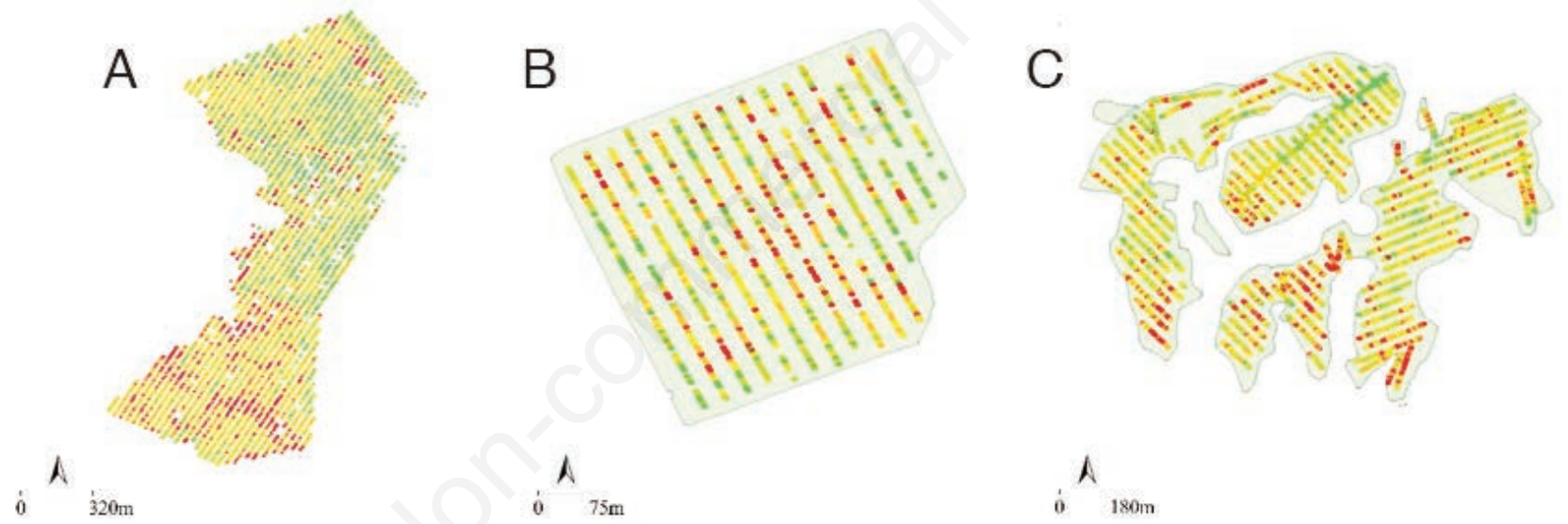

Figure 4. Electrical conductivity data collection points in areas A1 (A), A2 (B) and A3 (C).
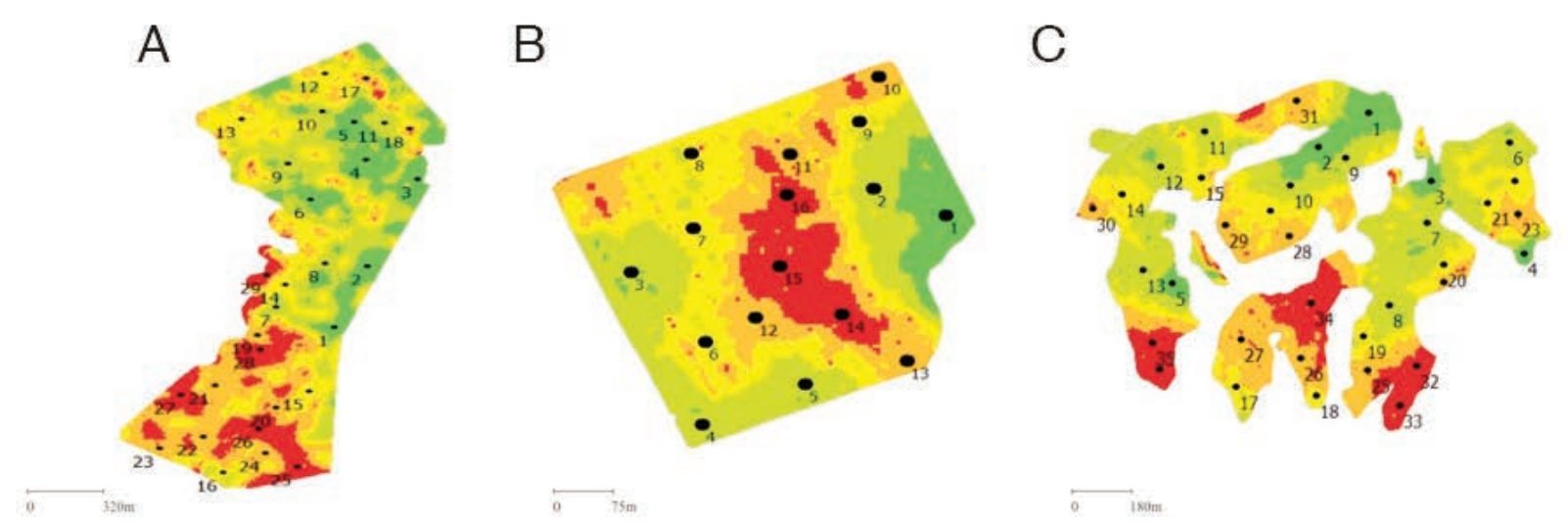

Figure 5. Management sampling zones for oriented sampling method for area A1 (A), A2 (B), and A3 (C). 
and the plant are fulfilled. Even though the plant uptakes the nutrient, it would still maintain the resources in the soil without causing any scarcity of soil content and making the production process more sustainable. The spatial distribution maps for the recommended dose of each element included 5 levels. For each area and for each element these 5 levels were the same for all the soil sampling methods in order to make them more easily comparable.

The desired content of phosphorus fertilization was intended to raise the levels in the soil to $8 \mathrm{mg} \mathrm{dm}^{-3}$. For potassium, the desired content was $0.3 \mathrm{cmol} \mathrm{dm}^{-3}$. For Nitrogen, it was based on the expected productivity in the region of the study from 12 to 14 tons of corn per hectare and organic matter content was above 4 to $6 \%$. These factors guided the fertilization recommendations based on availability for the plant and the system, with no deficit.

This fertilization correction process was based on Fontoura et al. (2015), who also stated that the $\mathrm{P}$ contents were low $<4$, medium from 4 to 8 and high $>8 \mathrm{mg} \mathrm{dcm}^{-3}$ and $\mathrm{K}$ contents were low $<0.15 \mathrm{cmol} \mathrm{dm}^{-3}$, medium 0.15 to 0.30 and high $>0.30 \mathrm{cmol} \mathrm{dm}^{-3}$.

In the GS method, interpolations were initially performed by punctual kriging (CELINSK, 2008) processed by software Vesper 1.6. Subsequently, the doses were obtained by chemical analysis for each zone, and then the final doses were calculated by multiplying the dose for each zone by its area based on the base saturation (BS) and cation exchange capacity (CEC) results. Then, doses were defined by each sampling point, generating in the end, from the sum of all the results, the total input dose in kilograms per hectare $\left(\mathrm{kg} \mathrm{ha}^{-1}\right)$. For better data analysis, the values were divided by 1000 to be presented in tons per hectare $\left(\mathrm{t} \mathrm{ha}^{-1}\right)$.

In the OS method, the definitions of the management zones were obtained through interpolated electrical conductivity maps by punctual kriging (CELINSK, 2008) using software Vesper 1.6, therefore it was possible to choose the best places for sampling. In the sequence, the traditional samplings were taken based on the information obtained from the maps. It should be emphasized that this was the method being tested, and therefore, there were no recommendation models as in the others.

Based on these analyses, the spatial distribution map of referred chemical elements and soil fertility maps were obtained for the three evaluated areas and with the three different studied sampling methods.

Based on the analysis of fertilizer recommendation maps, it was possible to compare quantitatively each fertilizer recommended for each sampling method by the total area of the evaluated plots.

\section{Results and discussion}

\section{Phosphorus}

As to the method applied in area A1 presented in Figure 6A-C, the OS was associated with a recommendation of $36.9 \mathrm{t}$ for the entire area, $4.3 \mathrm{t}$ more than with MZA and $2.6 \mathrm{t}$ more than with GS, and an even smaller spatial distribution on the recommendation map (Table 2). For area A1, OS did not show visually an environmental gain compared to the other methods; however, spatial variability (red spots, Figure 6C) on the recommendation map indicated a need of $10 \%(3.9 \mathrm{t})$ of $\mathrm{P}$ distributed in places not presented in previous methods.

In general, in terms of environmental impact, GS proved to be a more viable alternative for area $\mathrm{A} 1$ due to spatial distribution, even with a recommendation higher than for MZA. In Figure 6A, even with a lower P dose for MZA, it was not possible to observe a spatial distribution. In the map referring to sensor sampling
(Figure 6C), it was possible to observe two distribution scales of $\mathrm{P}$, although none were observed in MZA. The GS method presented all five recommended dose ranges of $\mathrm{P}$ application, thus showing a better distribution of $\mathrm{P}$ in the area under study. Even with the increase of $1.7 \mathrm{t}$, the most significant spatial distribution was shown in the map obtained by GS (Figure 6B). This indicated that the five interpretation ranges and some of them were not shown in the MZA map and in the OS map, which may indicate a P recommendation deficit, affecting productivity. Regarding the environmental impact, by comparing GS with MZA it is possible to see that for GS there would be an excess of $5.21 \%$ in P, but with a higher spatial distribution.

If the tree methods were compared using GS as reference for area A2 (Figure 6E), there would be a deficit of $0.2 \mathrm{t}$ for MZA (Figure 6D) and an overdosage of $1.5 \mathrm{t}$ for OS (Figure 6F). It was observed that all of the considered dose ranges were presenting in the GS a P recommendation map. Therefore, it could be considered as a more viable alternative to MZA due to its higher distribution, regardless of possible unnecessary doses in places presented by the MZA method.

When the orange color of the map generated by GS was compared with the red color of the MZA map, the possibility of $\mathrm{P}$ overdose was indicated by MZA and also a possible environmental impact, even with a recommendation of $0.2 \mathrm{t}$ lower due to the distribution. This information was obtained visually (qualitative) from the map and the results of $\mathrm{P}$ recommendations. It was possible to observe, in Figure 6D, through the red color that there would be approximately 0.2 ton of $\mathrm{P}$ unnecessarily applied when comparing to MZA with GS.

OS showed better distribution on the map (Figure 6F); however, it showed a considerably higher recommendation than the previous methods (1.7 $\mathrm{t}$ higher than MZA and $1.5 \mathrm{t}$ higher than GS). Therefore, the GS method could be considered as the most environmentally viable alternative, even with a distribution $0.2 \mathrm{t}$ higher than with MZA.

The recommendation map of $\mathrm{P}$, presented in Figure $6 \mathrm{H}$ for area A3, which was generated based on the GS method, presented all of the five recommended dose ranges of $\mathrm{P}$ application amounting in total to $8.2 \mathrm{t}$. Compared to the recommendations proposed by OS for area A3 (Figure 6I), similarly to the map generated from the MZA method (Figure 6H), it showed only two recommendation ranges totaling $15.3 \mathrm{t}$ for the entire area $\mathrm{A} 3$. Therefore, OS showed a recommendation for $\mathrm{P}$ of $7.8 \mathrm{t}$ more than MZA and $7.1 \mathrm{t}$ more than GS.

Considering only the Brazilian average of $30 \%$ of $\mathrm{P}$ application efficiency presented by Assad et al. (2012), regardless of the sampling method, there would be losses in the environment amounting to $22.82 \mathrm{t}$ for MZA, $24.01 \mathrm{t}$ for GS, and $25.83 \mathrm{t}$ for OS based on the results for area A1. For area A2, the losses would be $0.77 \mathrm{t}$ for MZA, $0.91 \mathrm{t}$ for GS, and 1.96 for OS, and for area A3 they would be $5.25 \mathrm{t}$ for MZA, $5.74 \mathrm{t}$ for GS, and $10.71 \mathrm{t}$ for OS. Therefore,

Table 2. Total application of phosphorus recommended by each soil sampling methods (altitude management zones, grid and oriented sampling) for area $\mathrm{A} 1, \mathrm{~A} 2$, and $\mathrm{A} 3$.

\begin{tabular}{cccc} 
Area & $\begin{array}{c}\text { Altitude } \\
\text { management } \\
\text { zones }\end{array}$ & $\begin{array}{c}\text { Phosphorus } \\
\text { Grid } \\
\text { sampling }\end{array}$ & $\begin{array}{c}\text { Oriented } \\
\text { sampling }\end{array}$ \\
$\mathrm{A} 1$ & 32.6 & 34.3 & 36.9 \\
$\mathrm{~A} 2$ & 1.1 & 1.3 & 2.8 \\
\hline $\mathrm{A} 3$ & 7.5 & 8.2 & 15.3 \\
\hline
\end{tabular}



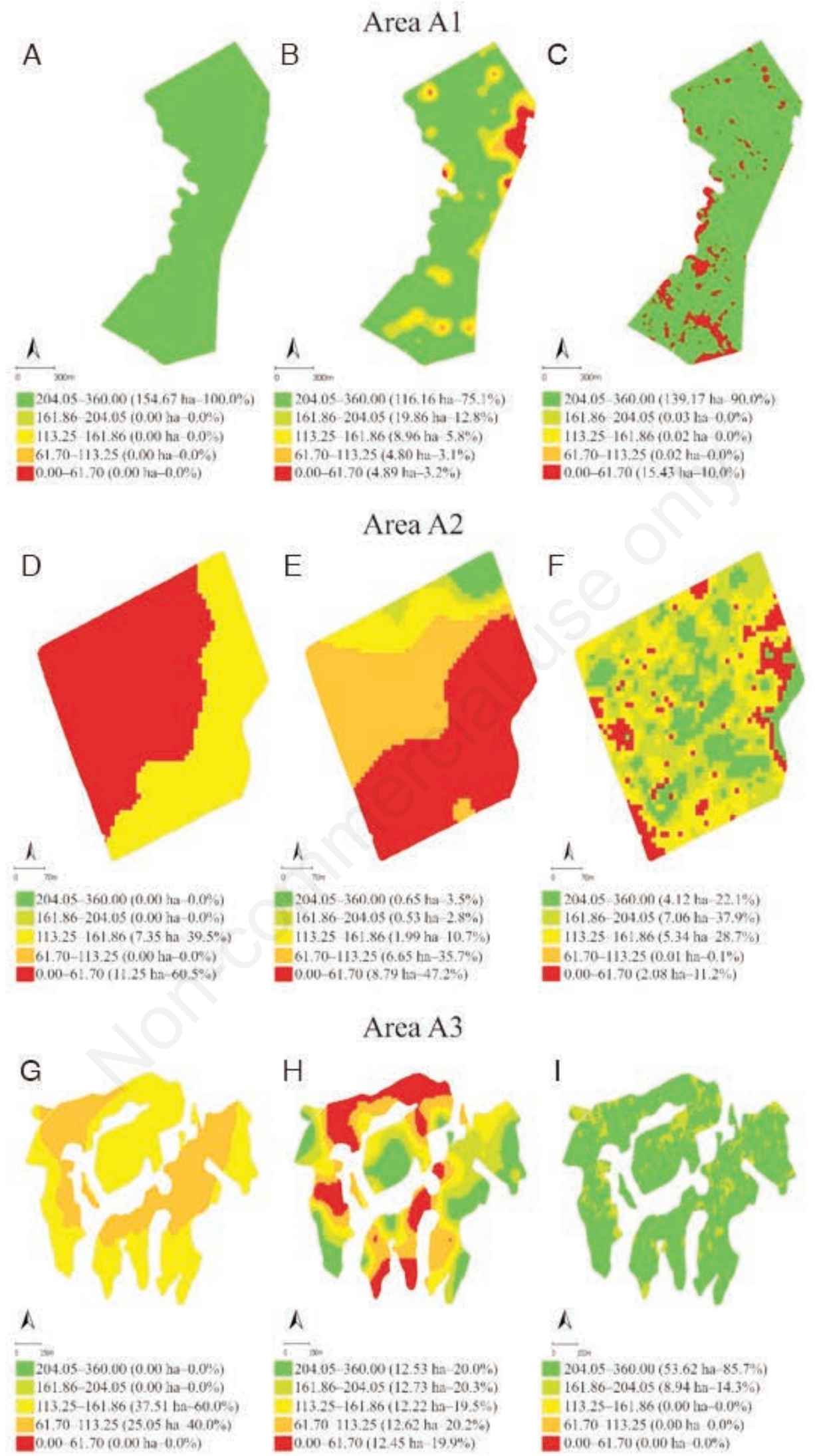

Figure 6. P recommendation maps obtained by the following sampling methods: MZA for area A1 (A), GS for area A1 (B), OS for area A1 (C), MZA for area A2 (D), GS for area A2 (E), OS for area A2 (F), MZA for area A3 (G), GS for area A3 (H), and OS for area A3 (I). 
besides the potential pollution due to inefficiency as already mentioned by the authors, there would be an additional contamination of $51 \%$ for MZA and $46.41 \%$ for GS, and especially eutrophication for the OS method.

GS was the most environmentally viable alternative, due to its spatial distribution and proportionality, in addition to having a recommendation value close to MZA. In this scenario, OS indicated the possibility of a higher $\mathrm{P}$ addition of $51 \%$ compared to MZA and $46.4 \%$ compared to GS for area A2, indicating a potential environmental damage in the future.

Klein and Agne (2012) calculated that the plants absorb only $15-20 \%$ of the applied phosphorus; the remaining 80 to $85 \%$ of losses are due to the mobility and solubility of $\mathrm{P}$ in water and the interaction between its particles and the soil. Considering this estimated loss already calculated for the environment, an excessive recommendation of $\mathrm{P}$ could cause disastrous environmental damage, in addition to the risk to human health due to the contamination of water bodies by leaching.

Although $\mathrm{P}$ shows a low percolation rate in the soil, it can cause an excessive enrichment of water and a consequent process of eutrophication due to surface runoff, if it is applied in excess. This situation can compromise oxygen availability in the medium due to an exaggerated growth of algae and plants. Therefore, eutrophication control measures are restricted by sizing correctly the amount of fertilizers to use (Klein and Agne, 2012).

It should be noted that $\mathrm{P}$ was applied directly to the sowing lines in all study areas, which should be avoided according to Klein and Agne (2012), since this is one of the most common sources of water contamination due to surface runoff leaching.

Soil erosion was not a specific problem in the studied areas. However, since phosphorus is applied directly to the superficial layer of the soil, it may be carried to the water bodies by the rain or irrigation, thus causing environmental problems.

The study conducted by Gebler et al. (2014) with commercial triple superphosphate to evaluate the transfer of $\mathrm{P}$ as contaminant concluded that most of soluble agricultural $\mathrm{P}$ is carried away during the initial rainy season. The authors concluded that $\mathrm{P}$ tends to be suspended at the beginning of the flood and dissolved in water over time, causing different scales of environmental risks in terms of surface runoff, especially in the case of heavy rain.

Research has also shown that inefficiencies of $\mathrm{P}$ are related to both incorrect application, such as in the areas under study, and excessive application. Therefore, the application of sampling techniques of PA that provide the correct dose of $\mathrm{P}$ is essential to minimize environmental impacts, particularly due to eutrophication.

\section{Potassium}

If we compare the three maps of $\mathrm{K}$ recommendations, it is possible to observe that the OS (Figure 7C) method was $5.1 \mathrm{t}$ higher than MZA (Figure 7A) and $3.8 \mathrm{t}$ higher than GS (Figure 7B) in the A1 area (Table 3). Therefore, GS proved to be the best alternative among all the methods, considering all distribution ranges, despite its recommendation is higher than in MZA. Moreover, MZA showed a potential $\mathrm{K}$ deficit.

Figure 7D-F represents the maps of $\mathrm{K}$ recommendation for the three sampling methods for area A2. The OS map (Figure 7E) reports values that are $2.5 \mathrm{t}$ higher than MZA and $2.4 \mathrm{t}$ higher than GS for the total area application. Therefore, as a whole GS proved to be the best alternative among the methods, even though it has only two interpretation ranges and has a recommendation which is higher than MZA. Moreover, MZA shows a potential K deficit.

For the area $\mathrm{A} 3$, according to the recommendation map of $\mathrm{K}$ generated based on the MZA (Figure 7G) method, a reduced spatial distribution of this element was identified. In contrast, MZA showed the lowest amount of $\mathrm{K}$ for area A3, with $2 \mathrm{t}$ lower than GS (Figure 7H) and $1.4 \mathrm{t}$ lower than OS (Figure 7I).

GS showed a greater spatial distribution in the map, covering all interpretation ranges, as well as several other areas not considered by MZA. OS also showed higher K distribution, as did GS, compared with all interpretation ranges on the map at sites not considered by MZA or GS.

In a general comparison among the three maps for area A3, MZA presented lower quantities of $\mathrm{K}$, and GS showed higher quantities of this nutrient. However, this was lower than in OS, which was shown as the most viable environmental alternative due to its greater spatial distribution, despite a higher $\mathrm{K}$ quantity and higher cost compared to MZA. Considering only the Brazilian average K application efficiency of $70 \%$ presented by Assad et al. (2012), regardless of the sampling method, there would be losses in the environment equal to $0.39 \mathrm{t}$ for GS, and $3.13 \mathrm{t}$ for OS, based on the results of area A1. For area A2, the losses would be $0.03 \mathrm{t}$ for GS and $0.75 \mathrm{t}$ for OS, and for area A3, $0.24 \mathrm{t}$ for MZA, $0.84 \mathrm{t}$ for GS, and $1.26 \mathrm{t}$ for OS.

Hauschild (2013) compared the recommendations of P and $\mathrm{K}$ for maize crops and demonstrated the efficiency of the use of grid samplings. Under- and oversized doses were verified in the results for different places and showed an excessive application of fertilizers, when the recommendations were based on the average.

$\mathrm{K}$ leaching is a real problem, because an excess of $\mathrm{K}$ can pollute groundwater (Silva et al., 2007) and, hence, the water table. For this reason, the doses of chemical recommendations must be reliable in order to avoid the pollution of water resources (Silva et al., 2007). It is also worth noting that the areas under study are rural areas in which groundwater is used for domestic consumption and irrigation, therefore this kind of pollution should be avoided.

Vargas (2012) reported that $\mathrm{K}$ could leach and penetrate the water table, thus increasing total dissolved solids, being soluble in water, and increasing salt concentration of the soil. Simplício (2015) also noted that the salinization process due to K might alter the composition of the local fauna, even at low concentrations, due to its high toxicity, highlighting in particular in the case of potassium chloride $(\mathrm{KCl})$.

By comparing and correlating the studied sampling methods, optimum $\mathrm{K}$ doses can be obtained in order to reduce the water table contamination by leaching of $\mathrm{KCl}$, and consequent salinization of these reservoirs.

\section{Nitrogen}

Figure 8A-C report the recommendation maps for methods MZA, GS, and OS, respectively.

The MZA presented two dose ranges. One of these dose range was impossible to see visually, because it was too much spread in the area. The GS map presented only one dose range, while the OS map presented two dose ranges. The total recommendation for $\mathrm{N}$ application to area A1 for the MZA method was $40.1 \mathrm{t}$, for the GS

Table 3. Total application of potassium recommended by each soil sampling methods (altitude management zones, grid and oriented sampling) for area A1, A2, and A3.

\begin{tabular}{lccc} 
Area & $\begin{array}{c}\text { Altitude } \\
\text { management } \\
\text { Zones }\end{array}$ & $\begin{array}{c}\text { Potassium } \\
\text { Grid } \\
\text { sampling }\end{array}$ & $\begin{array}{c}\text { Oriented } \\
\text { sampling }\end{array}$ \\
A1 & 0.0 & 1.3 & 5.1 \\
A2 & 0.0 & 0.1 & 2.5 \\
\hline A3 & 0.8 & 2.8 & 2.2 \\
\hline
\end{tabular}



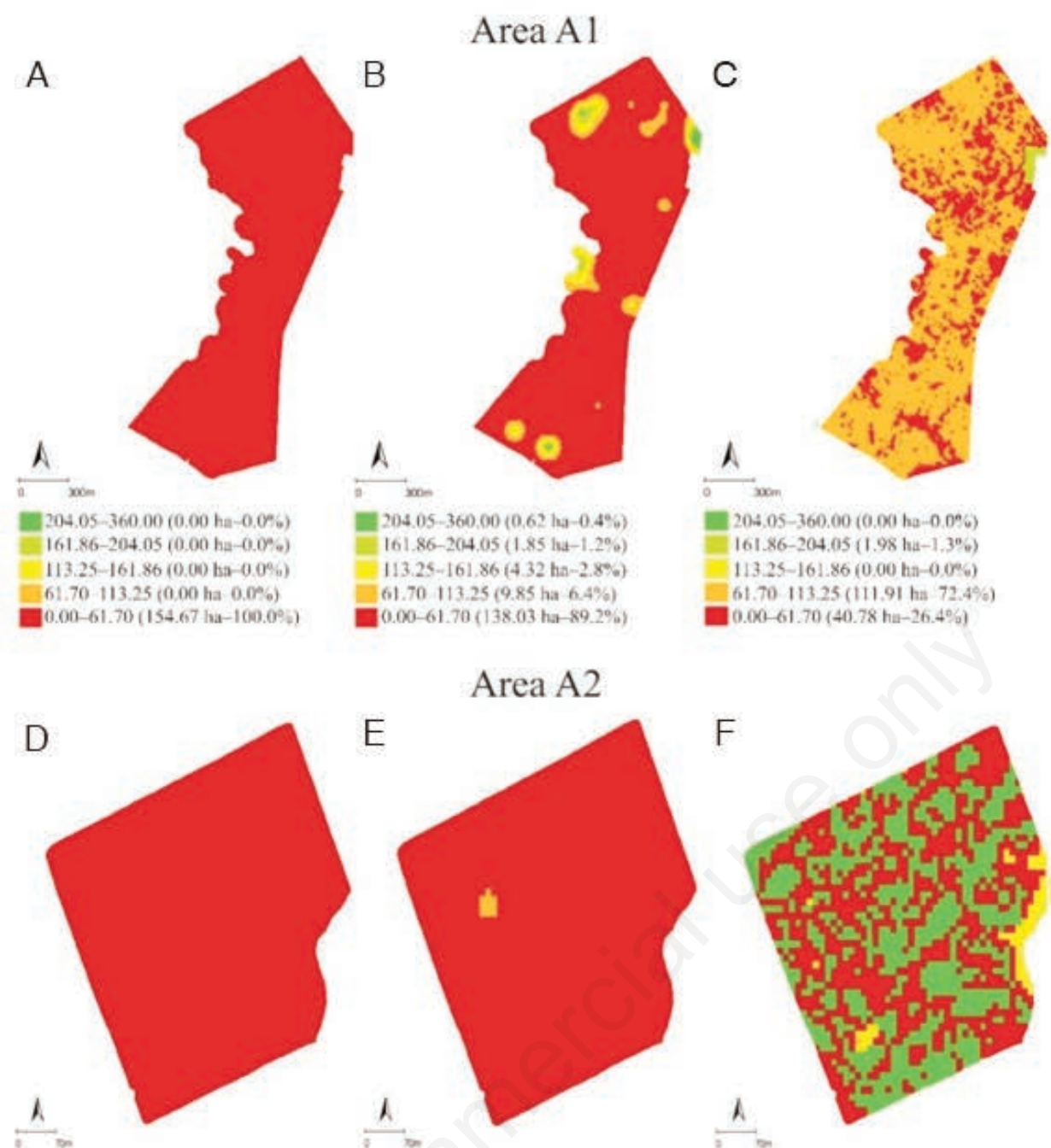

\section{Area A2}
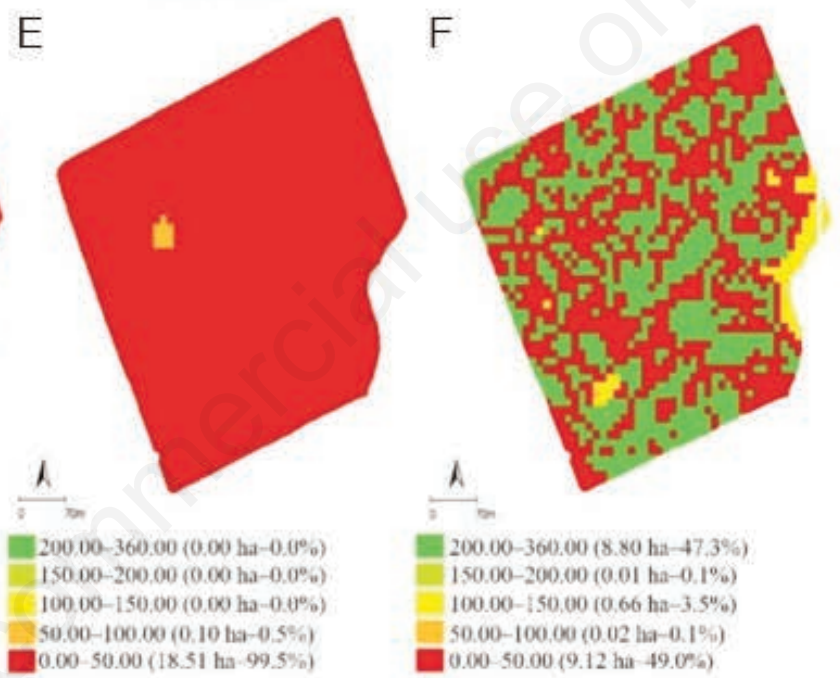

\section{Area A3}
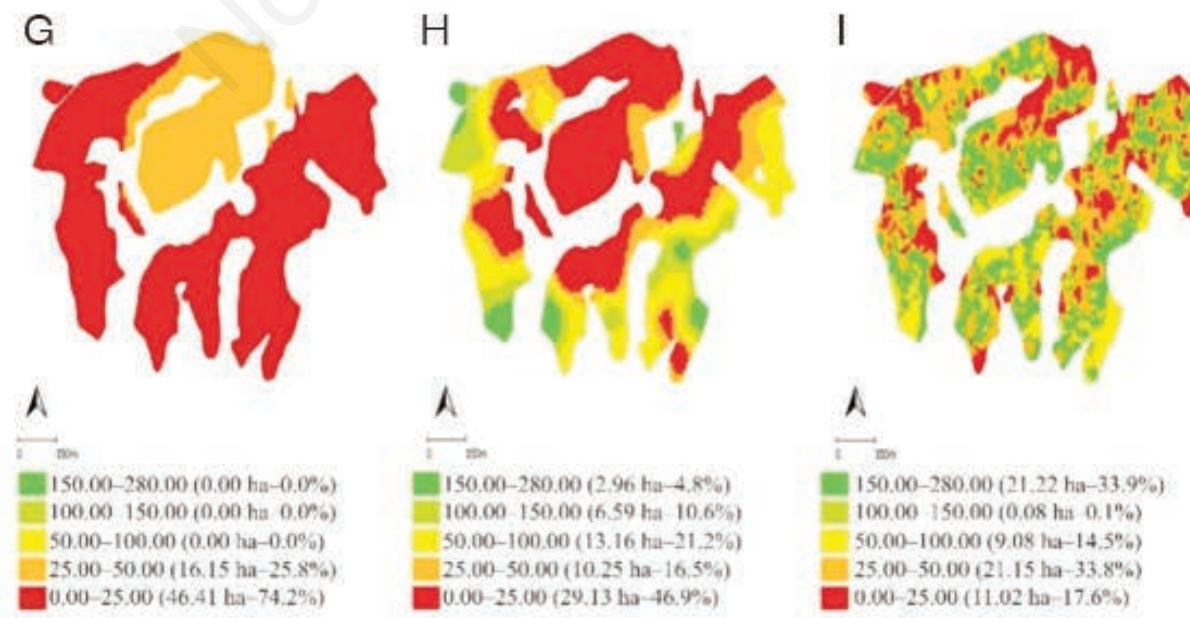

Figure 7. K recommendation maps obtained by the following sampling methods: MZA for area A1 (A), GS for area A1 (B), OS for area A1 (C), MZA for area A2 (D), GS for area A2 (E), OS for area A2 (F), MZA for area A3 (G), GS for area A3 (H), and OS for area A3 (I). 
method was $40.4 \mathrm{t}$, while for OS method it was $40.6 \mathrm{t}$ (Table 4).

Although the differences among the recommendations were considered non-significant in relation to the size of the areas, only the OS method showed spatial variability in its map (Figure 8C). For this reason, OS is presented as an alternative to the previous methods in terms of spatial variability.

The $\mathrm{N}$ recommendation map for area A2 regarding the MZA (Figure 8D) and GS (Figure 8E) have no difference from a visual point of view, with only one, recommended dose range of $\mathrm{N}$. The recommendation proposed by MZA was $4.8 \mathrm{t}$ for the entire area $\mathrm{A} 2$, whereas it was $4.9 \mathrm{t}$ according to the GS method. It was possible to observe that in the OS N recommendation map (Figure 8F) it presented two recommended dose ranges of $\mathrm{N}$ application, totaling $5.0 \mathrm{t}$ for the entire area A2. Although it was higher compared to the other two methods, it showed considerable spatial distribution in its map. The three methods presented a small total dose difference of only $0.1 \mathrm{t}$ for each method for the total area. Therefore, the OS method proved to be the most viable alternative from the environmental point of view, because it had more dose range classes and therefore represent better the spatial variability in the field and the actual $\mathrm{N}$ requirement of the soil.

The same situation observed for the area A1 and A2 could be observed in area A3. The MZA based map presented only one dose range, whereas the GS recommendation map presented two dose ranges, but in $2.6 \%$ of the area $\mathrm{A} 3$. The OS $\mathrm{N}$ recommendation map for area $\mathrm{A} 3$ also presented two dose ranges, but one of them represented $66.1 \%$ of the area, while the other represented $33.9 \%$. Once again, the OS method appeared to be the best method because it represented better the spatial variability of $\mathrm{N}$ in the field.

Considering the Brazilian average $\mathrm{N}$ application efficiency of $60 \%$ (Assad et al., 2012), regardless of the sampling method, there would be losses in the environment equal to $16.04 \mathrm{t}$ for MZA, $16.16 \mathrm{t}$ for GS, and $16.52 \mathrm{t}$ for OS based on the results of area A1. For area A2, the losses would be $1.92 \mathrm{t}$ for MZA and $1.96 \mathrm{t}$ for GS and OS, and for area A3, 6.52 $\mathrm{t}$ for MZA, $6.36 \mathrm{t}$ for GS, and $6.6 \mathrm{t}$ for OS.

By comparing the results of areas A1, A2, and A3, it was observed that the maps generated based on the MZA and GS methods were uniform, if we consider the expression of their total doses. On the other hand, OS showed a better spatial distribution of $\mathrm{N}$ in its maps, although it was associated with higher quantitative values comparing to other methods.

For this reason, when spatial distribution is evaluated from the environmental point of view, OS appears to be the most viable alternative compared to other methods. It is crucial to perform this kind of analysis, because nitrogen and its derivates might be very harmful to the environment. $\mathrm{N}$ is considered a dynamic nutrient with high soil solubility and mobility (Rambo et al., 2004), which, therefore, is susceptible to losses due to leaching, volatilization, immobilization, mobilization, nitrification, and denitrification (Biesdorf et al., 2016). Simplício (2015) stated that $\mathrm{N}$ fertilizers are alarming pollutants of aquatic ecosystems and can contaminate water organisms.

Studies performed by Kaiser et al. (2010) evaluated soil contamination by nitrates in tobacco planting in the Rio Grande do Sul, Brazil, and indicated high concentrations of this element, with a risk of water table contamination. Vargas (2012) pointed out that the yield loss, the economic value of the properties, and the risk to human health are related directly to the water table contamination. Nitrate leaching from $\mathrm{N}$ fertilization is susceptible to percolation and eutrophication, which convert it into nitrite.

The concern about $\mathrm{N}$ contamination related to over-application of $\mathrm{N}$ fertilizers is independent of the region, as nitrogen fertilizers are an important source of pollutants in aquatic ecosystems and their organisms are the main targets of this contamination.
Nitrate is one of the major contaminants reported in the literature concerning contamination. It represents a serious risk to human health, being a reliable indicator of potential contamination of the water table (Kaiser et al., 2010). It is a polluting mineral that contaminates groundwater through accumulation in the soil profile during the dry season, thus leaching in the rainy season (Silva et al., 2007), and can be carried to the water table and watercourses (Rambo et al., 2004), with disastrous environmental impacts (Bobato, 2006).

Costa and Guilhoto (2013) compared studies on the relationship between PA and the consequent reduction of environmental impacts from site-specific applications and found significant results, mainly related to $\mathrm{N}$ leaching. Such a reduction of $\mathrm{N}$ was between 13 and $50 \%$. However, the reduction in environmental contamination was higher than $50 \%$ in all of the reported studies, thus confirming the great potential of PA to reduce costs and environmental degradation and the importance of the topic investigated in this.

\section{Considerations about sampling methods}

According to Gomes and Barizon (2014), punctual concentrations of $\mathrm{N}, \mathrm{P}$, and $\mathrm{K}$ in the ionic form can trigger toxic effects for the biota, even in case of low toxicity in water bodies. In this study, $\mathrm{P}, \mathrm{K}$, and $\mathrm{N}$ were applied directly to sowing lines in all study areas and turned out that this could increase the contamination risk considerably due to surface runoff. Therefore, the application of PA sampling techniques that provide the correct dose of the fertilizer becomes essential to minimize environmental impacts to water bodies and the atmosphere.

For the MZA method, despite a large number of subsamples in each single sample, the resulting means from the recorded values may underestimate or overestimate some doses of each given input (Oliveira et al., 2008). It is possible that recommendations which are lower compared to the other methods do not suggest any actual environmental gain for MZA, but rather the possibility of recommendation deficit and yield decrease due to the choice of this method.

The GS method from georeferenced grids appeared to be a relevant environmental alternative for the recommendation of precise doses. The results obtained from GS were numerically higher than in MZA and lower than in OS in all comparisons. In most cases, GS provided more representative maps with spatial distribution which was superior to MZA.

Research performed by Sanchez et al. (2012) showed that the map generation for the application of inputs by variable rate was more economically and environmentally efficient, considering the mean-based applications. Furthermore, Cherubin et al. (2015) emphasized that soil fertility maps decrease similarities according to the increase of the grid sampling, with more significant deviations for $\mathrm{P}$ than for $\mathrm{K}$.

Table 4. Total application of nitrogen recommended by each soil sampling methods (altitude management zones, grid and oriented sampling) for area $\mathrm{A1}, \mathrm{A} 2$, and $\mathrm{A} 3$.

\begin{tabular}{lccc} 
Area & $\begin{array}{c}\text { Altitude } \\
\text { management } \\
\text { Zones }\end{array}$ & $\begin{array}{c}\text { Nitrogen } \\
\text { Grid } \\
\text { sampling }\end{array}$ & $\begin{array}{c}\text { Oriented } \\
\text { sampling }\end{array}$ \\
$\mathrm{A} 1$ & 40.1 & 40.4 & 40.6 \\
$\mathrm{~A} 2$ & 4.8 & 4.9 & 5.0 \\
\hline $\mathrm{A} 3$ & 16.3 & 15.9 & 16.5 \\
\hline
\end{tabular}



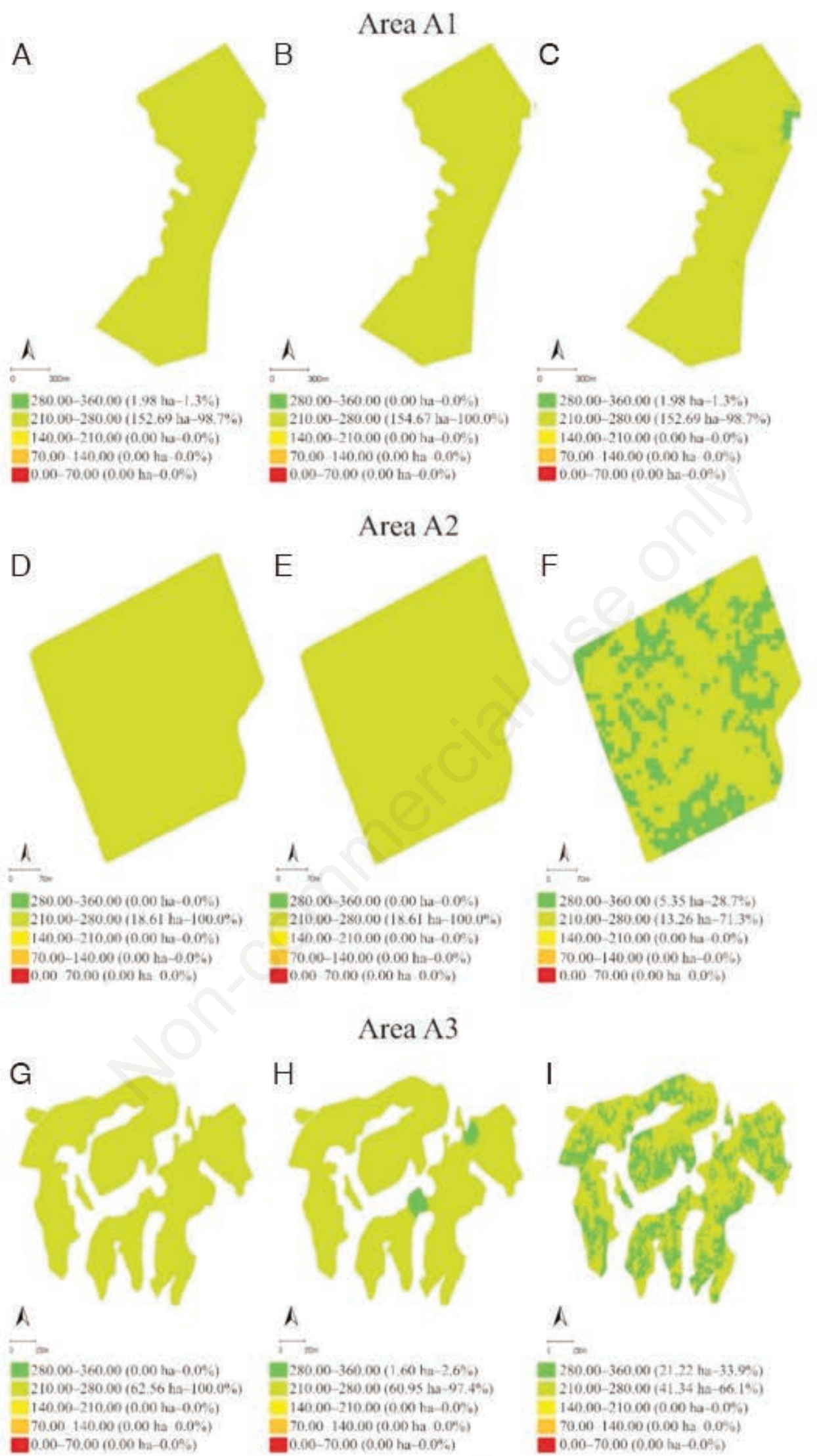

Figure 8. $\mathrm{N}$ recommendation maps obtained by the following sampling methods: MZA for area A1 (A), GS for area A1 (B), OS for area A1 (C), MZA for area A2 (D), GS for area A2 (E), OS for area A2 (F), MZA for area A3 (G), GS for area A3 (H), and OS for area A3 (I). 
By studying the reduction of environmental impacts promoted by PA in soybean crops, Artuzo (2014) observed that the use of K and $\mathrm{P}$ was reduced in $100 \%$ on the studied areas, with an average reduction of $33.1 \%$. Artuzo (2015) evaluated the soybean crop in the Rio Grande do Sul, Brazil, in 81 rural properties, and observed that $82 \%$ of farmers already performed georeferenced sampling. However, only $14.8 \%$ performed sowing by variable-rate, and $33.33 \%$ were interested in the fertilizer recommendation by variable rates. Sapkota et al. (2014) observed that most farmers tend to apply higher $\mathrm{P}$ and $\mathrm{N}$ rates frequently, thus making leaching become an alarming factor.

The OS method was presented as a superior alternative to MZA, providing recommendation maps based on ECa. Such superiority is possible because the OS offers an improvement on the conventional method, with management zones defined by PA technology and more efficient recommendations, because it does not only consider elevations in the definition of management zones, as proposed by the MZA.

In general, OS provided proper visual distribution in all recommendation maps, however, except for $\mathrm{N}$ recommendation in area A1, it was associated with doses higher than MZA and GS for P, $\mathrm{K}$, and $\mathrm{N}$ for all areas.

Research performed by Artuzo (2015) demonstrated that only $51 \%$ of farmers are interested in the use of soil sensors and indicated the cost of the analyses as a limiting factor of PA.

Increasingly precise doses and guided applications are required in order to meet the soil needs in a heterogeneous way, without considering a total area as a reference for average fertilization. All of the studied soil sampling methods take into account this heterogeny. In this scenario, GS was presented as the most viable alternative for $\mathrm{P}$, and OS was the most viable for $\mathrm{K}$ and $\mathrm{N}$, in general, when considering the environmental impacts.

Probably no producer will apply different sampling strategies for the single fertilizer elements, therefore they will have to rely on the elements that could present the worst potential environmental impact for their specific areas. They will have to take into account soil type, soil depth, presence of water bodies, declivity, the possibility of runoff and soil erosion, etc. Also, they will have to study which element can cause a major environmental impact in their area and then choose the best soil sampling strategy for all elements.

Notably, studies on PA have evolved and tend to show economic and environmental benefit at present and in the future. However, PA sampling methods need further improvement in order to provide yield, cost reduction, and consequent economic and environmental gain, in order to guarantee present and future generations with adequate natural resources.

\section{Conclusions}

It was possible to compare the sampling methods from the environmental point of view based on altitude management zones, grid samplings, and sensor-oriented samplings by ECa of the soil. It was possible to observe a significant difference among the doses suggested by each soil sampling method. Therefore, it is necessary to improve the soil sampling techniques in order to clear up all doubt related to deficits or overdoses in the application of inputs, regardless of the chosen technology in the present study. In conclusion, the GS soil sampling method appeared to be the best environmental alternative for $\mathrm{P}$, and $\mathrm{OS}$ for $\mathrm{K}$ and $\mathrm{N}$.

\section{References}

Artuzo F.D. 2015. Análise da eficiência técnica e econômica da agricultura de precisão a taxa variável de fertilizantes na cultura da soja no RJ. Master's Thesis, Federal University of Rio Grande do Sul, Brazil.

Artuzo F.D., Jandrey W.F., Silva L.X. 2014. Impacto da agricultura de precisão a taxa variável na cultura da soja: questões produtivas e ambientais. pp 146-161 in Proc. $2^{\circ}$ Simpósio da Ciência do Agronegócio, Porto Alegre, RS, Brazil.

Assad E.D., Martins S.C., Pinto H.S. 2012. Sustentabilidade no Agronegócio Brasileiro: Coleção de Estudos sobre Diretrizes para uma Economia Verde no Brasil. 1st ed. Fundação Brasileira para o Desenvolvimento Sustentável, Rio de Janeiro, RJ, Brazil.

Beras G. 2014. Economic viability analysis of the soybean crop seeding using fertilizer variable rate in the furrow. Master's Thesis, Federal University of Santa Maria, Brazil.

Biesdorf E.M., Teixeira M.F.F., Dietrich O.H., Pimentel L.D., Araujo C.D. 2016. Nitrogen application methods on the maize crop in cerrado soil. Rev. Agric. Neotrop. 3:44-50.

Bobato A. 2006. Índice nutricional do Nitrogênio: uma ferramenta para o diagnóstico do estado nutricional da cultura do milho. Master's Thesis, Federal University of Paraná, Brazil.

Catania P., Comparetti A., Febo P., Morello G., Orlando S., Roma E., Vallone M. 2020. Positioning accuracy comparison of GNSS receivers used for mapping and guidance of agricultural machines. Agronomy 10(7):doi:10.3390/agronomy10070924.

Celinski V.G. 2008. Evaluation of an electric measure sensor using correlation with soil attributes. Dissertation. São Paulo State University, Brazil.

Cherubin M.R., Santi A.L., Eitelwein M.T., Amado T.J.C., Simon D.H., Damian J.M. 2015. Sampling grid size for characterization of the spatial variability of phosphorus and potassium in an Oxisol. Pesqui. Agropecu. Bras. 50:168-77.

Costa C.C., Guilhoto J.J.M. 2013. Impactos potenciais da agricultura de precisão sobre a economia brasileira. Rev. Eco. Agro. 10:177-204.

Crookston R.K. 2006. A top 10 list of developments and issues impacting crop management and ecology during the past 50 years. Crop Sci. 46:2253-62.

Empresa Brasileira de Pesquisa Agropecuária, 1997. Manual de métodos de análise de solos. 2nd ed. Centro Nacional de Pesquisa de Solos, Rio de Janeiro, RJ, Brazil.

Ferraz G.A.S., Barbosa B.D.S., Reynaldo E.F., Santos S.A., Goncalves J.R.M.R., Ferraz P.F.P. 2019. Spatial variability of soil $\mathrm{pH}$ sampled by two methodologies used in precision agriculture in farms under crop rotation. Dyna 86:289-97.

Fontoura S.M.V., Vieira R.C.B., Bayer C., Viero F., Anghinoni I., Moraes R.P., 2015. Fertilidade do solo e seu manejo em sistema plantio direto no Centro-Sul do Paraná. 1st ed. Fundação Agrária de Pesquisa Agropecuária, Guarapuava, PR, Brazil.

Gebler L., Bertol I., Biasi L.R.D., Ramos R.R., Louzada J.A.S. 2014. Superficial loss of reactive phosphorus potentially contaminant by intense rainfall simulation. Eng. Sanit. Ambient. 19:393-399.

Gomes M.A.F., Barizon R.R.M. 2014. Panorama da contaminação Ambiental por Agrotóxicos e nitrato de origem agrícola no Brasil: Cenário 1992/201. 1st ed. Embrapa Meio Ambiente, Jaguariúna, SP, Brazil.

Hauschild F.G. 2013. Precision farming techiniques for definiton management zones of soil. Master's Thesis. Federal University of Santa Maria, Brazil.

Kaiser D.R., Reinert D.J., Reichert J.M., Streck C.A., Pellegrini A. 
2010. Nitrate and ammonium in soil solution in tobacco management systems. Rev. Bras. Cienc. Solo 34:379-88.

Keskin M., Sekerli Y.E. 2016. Awareness and adoption of precision agriculture in the Cukurova region of Turkey. Agron. Res. 14:1307-20.

Klein C., Agne S.A.A. 2012. Phosphorus: from the nutrient to pollutant! Rev. Eletrônica Gest. Educ. Tecnol. Ambient. 8:171321.

Machado P.L.O.A., Bernardi A.C.C., Valencia L.I.O., Molin J.P., Gimenez L.M., Silva C.A., Andrade A.G., Madari B.E., Meirelles M.S.P. 2006. Electrical conductivity mapping in relation to clay of a Ferralsol under no tillage system. Pesq. Agropec. Bras. 41:1023-31.

Mallarino A.P., Wittry D.J. 2004. Efficacy of grid and zone soil sampling approaches for site-specific assessment of phosphorus, potassium, $\mathrm{pH}$, and organic matter. Precis. Agric. 5:13144.

Miqueloni D.P., Gianello E.M., Bueno C.R.P. 2015. Variabilidade espacial de atributos e perda de solo na definição de zonas de manejo. Pesq. Agropec. Trop. 45:18-28.

Mulla D.J. 2013. Twenty-five years of remote sensing in precision agriculture: Key advances and remaining knowledge gaps. Biosyst. Eng. 114:358-71.

Oliveira R.B.D., Lima J.S.D.S., Xavier A.C., Passos R.R., Silva D.A.S., Silva A.F.D. 2008. Comparison between soil sampling methods for conilon coffee liming and fertilization recommendation. Eng. Agríc. 28:176-86.

Pierce F.J., Nowak P. 1999. Aspects of precision agriculture. Adv. Agron. 67:1-86.

Pierpaoli E., Carli G., Pignatti E., Canavari M. 2013. Drivers of precision agriculture technologies adoption: a literature review. Proc. Technol. 8:61-9.

Prado E.V., Machado T.A., Prado F.M.T. 2015. Geração e correlação de zonas de manejo usando sensor spad e condutividade elétrica aparente do solo para a cafeicultura irrigada na zona da mata mineira. Rev. Cient. Eletr. Agron. 1:1-7.

Ragagnin V.A., Sena Júnior D.G., Silveira Neto N.A. 2010. Recommendation of liming at variable rates under different sampling intensities. Rev. Bras. Eng. Agr. Amb. 14:600-7.
Rambo L., Silva P.R.F., Argenta G., Sangoi L. 2004. Plant parameters to refine the management of nitrogen side-dress application in maize. Cienc. Rural 34:1637-45.

Sanchez R.B., Marques Júnior J., Pereira G.T., Baracat Neto J., Siqueira D.S., Souza Z.M.D. 2012. Mapping the relief forms to estimate the fertilization expenses in sugarcane. Eng. Agríc. 32:280-92.

Sapkota T.B., Majumdar K., Jat M.L., Kumar A., Bishnoi D.K., McDonald A.J., Pampolino M. 2014. Precision nutrient management in conservation agriculture based wheat production of Northwest India: Profitability, nutrient use efficiency and environmental footprint. Field Crops Res. 155:233-44.

Silva C.B. 2009. Innovation in the sugarcane industry of São Paulo state: determiners to adopt technologies of precision agriculture. Dissertation. University of São Paulo, Brazil.

Silva M.A.S.D., Griebeler N.P., Borges L.C. 2007. Use of stillage and its impact on soil properties and groundwater. Rev. Bras. Eng. Agríc. Ambient. 11:108-14.

Simplício N. 2015. Fertilizers ecotoxicity: A comparative analysis of nitrogen, phosphorus and potassium-based products and its active ingredients separately. Master's Thesis. University of Brasília, Brazil.

Vargas G.R. 2012. Potassium fertilization effect on soybean yield. Publ. UEPG Ci. Exatas Terra, Ci. Agr. Eng. 18:79-84.

Walton J.C., Roberts R.K., Lambert D.M., Larson J.A., English B.C., Larkin S.L., Martin S.W., Marra M.C., Paxton K.W., Reeves J.M. 2010. Grid soil sampling adoption and abandonment in cotton production. Precis. Agric. 11:135-47.

Wang J., Lu X., Feng Y., Yang R. 2018. Integrating multi-fractal theory and geo-statistics method to characterize the spatial variability of particle size distribution of minesoils. Geoderma 317:39-46.

Zhang Q., Yang Z., Li Y., Chen D., Zhang J., Chen M. 2010. Spatial variability of soil nutrients and GIS-based nutrient management in Yongji County, China. Int. J. Geogr. Inf. Sci. 24:965-81.

Zinkevičius R. 2018. Influence of soil sampling for precision fertilizing. Agron. Res. 6:423-9. 